\author{
M. Sollberger \\ F. Fluri \\ T. Baumann \\ S. Sonnet \\ M. Tamm \\ A. J. Steck \\ M. Brutsche
}

\section{Successful treatment of steroid-refractory neurosarcoidosis with infliximab}

Received: 20 November 2003

Received in revised form: 21 January 2004

Accepted: 6 February 2004

Sirs: Sarcoidosis is a systemic, granulomatous disorder of unknown origin, rarely affecting the nervous system [1]. There are patients with chronic disease whose course is progressive while on therapy with corticosteroids and immunosuppressive medicaments [2]. Several lines of evidence indicate that tumor-necrosis factor- $\alpha$ (TNF$\alpha$ ) plays a key role in the inflammatory process of some human autoimmune diseases [3]. Infliximab, a chimeric monoclonal humanmurine IgG antibody directed specifically against TNF- $\alpha$, has proved effective not only in refractory rheumatoid arthritis and Crohn's disease, but also in systemic sarcoidosis $[4,5]$. We report a case of neurosarcoidosis refractory to previous treatments in which infliximab was associated with a markedly improved clinical outcome.

In April 2001 a 45-year-old man developed slowly progressive numbness and paresthesia of the feet, ascending to the knee, erectile dysfunction and adynamia. Unsteadiness in walking and pares-

$\approx$ thesia of the hands followed rapidly. Examination in October 2001 showed signs of a right vestibulo-cochlear dysfunction together with distally pronounced sensory disturbances of the lower extremities and gait ataxia.

Laboratory investigations disclosed a hypogonadotropic hypogonadism. The cerebrospinal fluid analysis revealed an elevated protein level of $4344 \mathrm{mg} / \mathrm{L}$ (normal $180-480 \mathrm{mg} / \mathrm{L}$ ), a lymphocytosis of $47 \times 10^{6} / \mathrm{L}\left(<4.7 \times 10^{6} / \mathrm{L}\right)$ and an elevated serum angiotensin-converting enzyme of $8 \mathrm{U} / \mathrm{L}(<3 \mathrm{U} / \mathrm{L})$. Nerve conduction studies indicated a demyelinating, sensorimotor polyneuropathy of the upper and lower extremities. MRI of the brain revealed a prominent infundibulum with homogeneous gadolinium-enhancement. MRI of the lumbar spinal cord showed no pathology. Computed tomography of the chest disclosed bilateral hilar and mediastinal lymphadenopathy with normal lung parenchyma. Biopsy findings of a hilar lymph node were consistent with sarcoidosis.

The patient was treated with oral prednisone $50 \mathrm{mg}$ daily, leading to an about $50 \%$ regression of the sensory symptoms within 3 months. Because of a Cushing's syndrome, associated with osteopenia, azathioprine (200 mg/day) was initiated in February 2002 in conjunction with prednisone taper to $10 \mathrm{mg} /$ day.

Three months later the patient developed a subacute conus-syndrome with an arachnoiditis at the conus-cauda level (Fig.). Administration of intravenous methylprednisolone ( $500 \mathrm{mg} /$ day for 3 days), followed by augmentation of prednisone to $20 \mathrm{mg} /$ day was without effect. Over the next 6 months the sensory disturbances, the vertigo and the unsteadiness in walking progressed.

Because of the continuous deterioration of the neurological condition while on immunosuppressive therapy, infliximab (500 mg,
$5 \mathrm{mg} / \mathrm{kg}$ of body weight) was administered intravenously in February 2003 in conjunction with azathioprine taper to $50 \mathrm{mg} /$ day. Infliximab was given again at 2,8 , 14,20 and 26 weeks without adverse effects. A few days after the first dose the numbness of the feet and the fatigue diminished, followed within weeks by regression of the gait ataxia and within months by regression of the autonomic dysfunctions.

Examination in September 2003, after 6 infliximab applications, showed diminution of the right vestibulo-cochlear dysfunction, the spinal cord symptoms and the gait ataxia. The distally pronounced sensory disturbances of the lower extremities were similar to those at the onset of the disease. MRI of the lumbar spinal cord and the brain disclosed complete resolution of the lesions (Fig.) and cerebrospinal fluid analysis showed a normalization of the cell number $\left(3 \times 10^{6} / \mathrm{L}\right)$ and a decrease of the protein level to $904 \mathrm{mg} / \mathrm{L}$. Nerve conduction studies showed no significant improvement compared to baseline.

Our patient presented with a biopsy-proven progressive neurosarcoidosis, involving the hypophysis, the right vestibulocochlear nerve, the spinal cord and the peripheral nervous system, refractory to corticosteroids and azathioprine. He experienced a remarkable clinical improvement with infliximab. There were no adverse effects associated with infliximab. Our findings are consistent with two recent case reports in which infliximab proved effective for patients with refractory neurosarcoidosis $[6,7]$. 

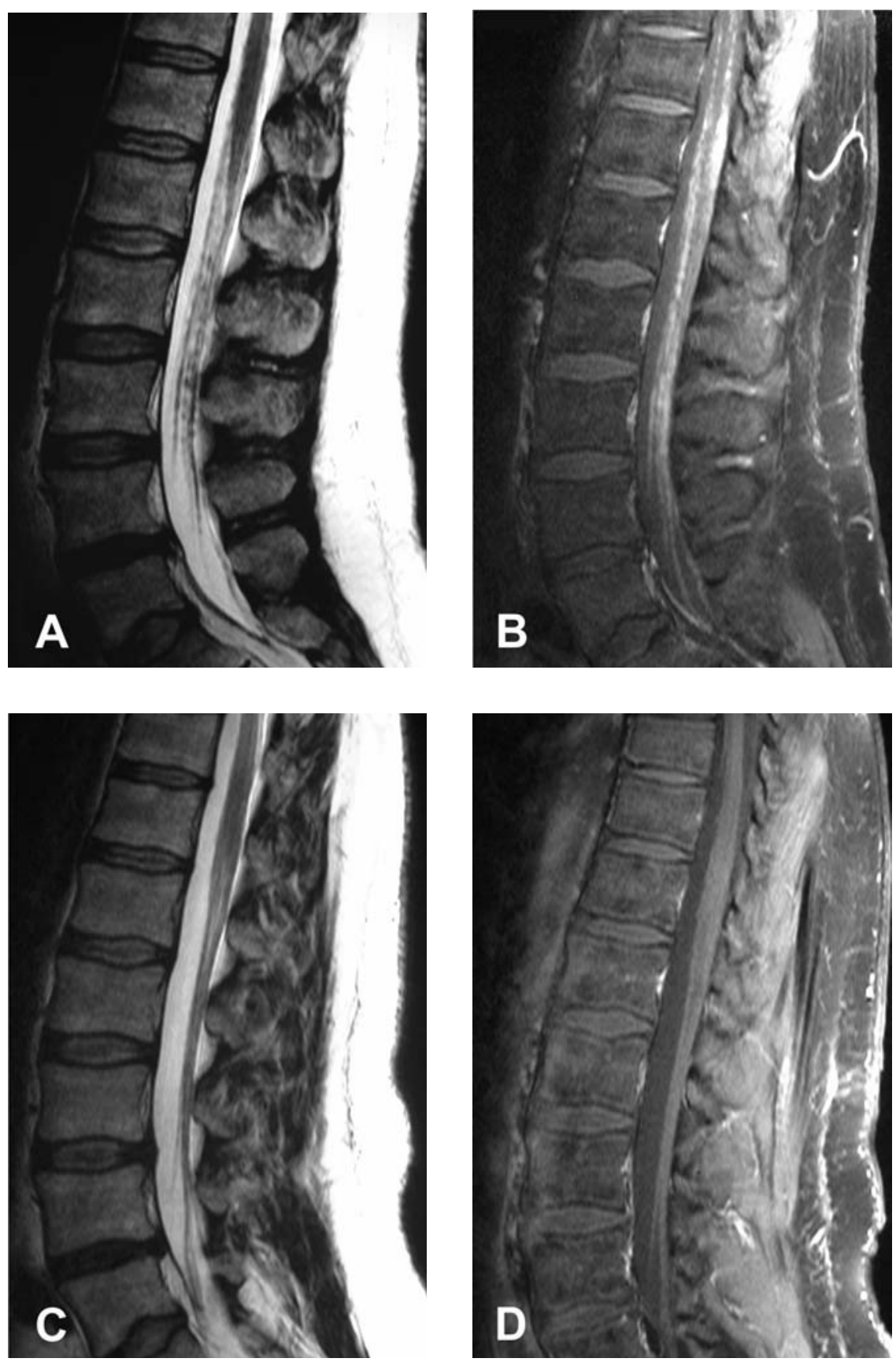

Fig. Initial and post-treatment MRI-studies: Sagittal T2 weighted (A) and contrast-enhanced T1 weighted (B) MRI of lumbar spine before treatment show nodular hypointense, contrast-enhanced leptomeningeal lesions surrounding conus and cauda equina with enlargement at the conus-cauda level. Post-treatment sagittal T2 weighted (C) and contrast-enhanced T1 weighted (D) MRI of lumbar spine show complete remission of the lesions with normal appearance of the conus and cauda equina.

\section{References}

1. Lower EE, Broderick JP, Brott TG, Baughman RP (1997) Diagnosis and management of neurological sarcoidosis. Arch Intern Med 157:1864-1868

2. Zajicek JP, Scolding NJ, Foster O, Rovaris M, Evanson J, Moseley IF, et al. (1999) Central nervous system sarcoidosis-diagnosis and management. QJ Med 92:103-117

3. Andreakos ET, Foxwell BM, Brennan FM, Maini RN, Feldmann M (2002) Cytokines and anti-cytokine biologicals in autoimmunity: present and future. $\mathrm{Cy}$ tokine Growth Factor Rev 13:299-313

4. Baughman RP, Lower EE (2001) Infliximab for refractory sarcoidosis. Sarcoidosis Vasc Diffuse Lung Dis 18:70-74

5. Yee AM, Pochapin MB (2001) Treatment of complicated sarcoidosis with infliximab anti-tumor necrosis factor-alpha therapy. Ann Intern Med 135:27-31

6. Pettersen JA, Zochodne DW, Bell RB, Martin L, Hill MD (2002) Refractory neurosarcoidosis responding to infliximab. Neurology 59:1660-1661

7. Katz JM, Bruno MK, Winterkorn JM, Nealon N (2003) The pathogenesis and treatment of optic disc swelling in neurosarcoidosis: a unique therapeutic response to infliximab. Arch Neurol $60: 426-430$

M. Sollberger $(\bowtie) \cdot$ F. Fluri · T. Baumann · A. J. Steck

Department of Neurology

University Hospital

Petersgraben 4

4031 Basel, Switzerland

Tel.: + 41-61/265-5431

Fax: + 41-61/265-4491

E-Mail: marcsollberger@hotmail.com

\section{S. Sonnet}

Department of Neuroradiology

University Hospital

Petersgraben 4

4031 Basel, Switzerland

M. Tamm $\cdot$ M. Brutsche

Department of Pneumology

University Hospital

Petersgraben 4

4031 Basel, Switzerland 